Тези конференції / Conference Abstract • The Interventional Pain Management Conference, Kyiv, Ukraine , May, 16-17, 2019

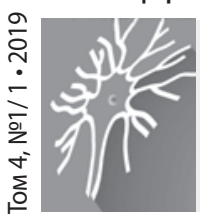

\title{
PainMedicine Journal
}

Медицина Болю // Медицина Боли

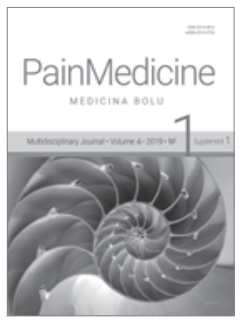

DOI: $10.31636 /$ pmjua.t2.14

\section{Ultrasound guided bilateral erector spinae plane block for post-surgical pain in patients after thoracic surgery}

\author{
Dmytriiev D. V., Glazov E. O., Marchuk O. V., Zaletskiy B. V. \\ National Pirogov Memorial Medical University, Vinnytsia, Ukraine
}

Objective: To examine the analgesic efficacy of bilateral erector spinae plane (ESP) block compared with conventional treatment for pain after thoracic surgery.

Methods: 34 patients with thoracic trauma were divided into 2 groups. Patients in group 1 (ESP block group, $n=14$ ) received ultrasound-guided bilateral ESP block with $3 \mathrm{mg} / \mathrm{kg}$ of $0.375 \%$ ropivacaine before anesthesia induction at the $\mathrm{T} 6$ transverse process level (Fig. 1). Patients in group 2 (acetaminophen and morphin group, $\mathrm{n}=20$ ) received acetaminophen $(15 \mathrm{mg} / \mathrm{kg}$ every 6 hours - maximum $1 \mathrm{~g}$ ) and morphine (10 mg every 8 hours) intravenously in the postoperative period. The primary study outcome was to evaluate pain at rest using an 10-point numeric rating scale (NRS). Mann - Whitney U-test was used for comparing NRS scores.

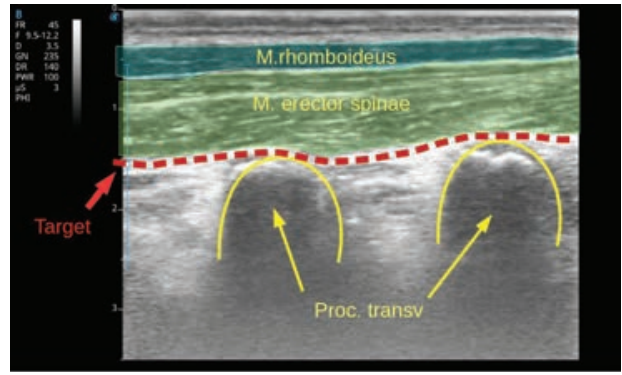

Fig. 1. Erector spinae block ultrasound image
Results: The postoperative pain level after extubation and duration of analgesia during which NRS was $<4$ of 10 was compared between the groups. The median pain score at rest after extubation in group 1 was 0 of 10 until hour 6,3 of 10 at hour 8 , and 4 of 10 at hours 10 and 12 postextubation. These were significantly less in comparison with group 2 $(p=0.0001)$. Patients in group 1 had a significantly higher mean duration of analgesia (11.04 \pm 0.18 hours), during which NRS was $<4$ of 10 , compared with group $2(4.18 \pm 0.14$ hours $)(p=0.0001)$.

Conclusion: ESP block safely provided significantly better pain relief at rest for longer duration as compared to intravenous acetaminophen and morphine.

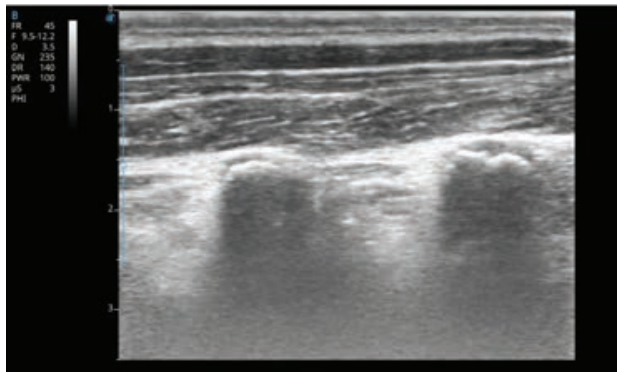

